\title{
autêntica
}

ARTIGOS

\section{Impactos do trabalho de pesquisa colaborativo na formação e no desenvolvimento profissional de professores de Matemática no Projeto OBEDUC Núcleo UEPB}

Abigail Fregni Lins

\begin{abstract}
RESUMO
O Programa OBEDUC da CAPES tem como meta fomentar estudos e pesquisas em educação que utilizem a infraestrutura disponível das instituições de educação superior e bases de dados existentes no INEP. Tem como objetivos proporcionar a articulação entre pós-graduação, licenciaturas e escolas de educação básica, estimular a produção acadêmica e a formação de recursos pós-graduados, em nível de mestrado e doutorado. Neste sentido, discutimos em nosso artigo resultados da aplicação de questionários, dos quais relatamos impactos do trabalho de pesquisa colaborativo na formação de dois dos oito graduandos e no desenvolvimento profissional de dois dos oito professores de Matemática inseridos no Projeto OBEDUC em rede Edital 2012 Núcleo UEPB nos últimos três anos. Foi de experiência única e enriquecedora aos professores em formação e em exercício terem tido a oportunidade de inserção ativa em um projeto envolvendo pesquisa na educação. Os resultados comprovam a vital importância de apoio governamental para recursos financeiros de atividades no desenvolvimento pré-profissional e profissional de professores, assim como recursos financeiros de atividades na pesquisa. Podemos afirmar fortemente que a implantação do Programa OBEDUC na CAPES provoca e problematiza novos rumos nas políticas educacionais de formação de professores e pesquisadores de nosso país ao proporcionar interação e trabalho de forma conjunta, ao integrar alunos de graduação, de pós-graduação e professores em exercício em um mesmo projeto, em um mesmo processo, com um mesmo objetivo. Acreditamos que o Programa OBEDUC da CAPES se dá, e pode ser entendido, como uma área de estudo para políticas educacionais da educação superior de nosso país, tanto a nível graduação como a nível pós-graduação, como para o desenvolvimento profissional de professores.
\end{abstract}

\section{PALAVRAS-CHAVE}

OBEDUC, Educação Matemática, Pesquisa, Desenvolvimento Profissional, Formação de Professores.

\section{COLLABORATIVE RESEARCH WORK IMPACTS ON THE EDUCATION AND PROFESSIONAL DEVELOPMENT OF MATHEMATICS TEACHERS FROM THE OBEDUC PROJECT CORE UEPB}

\begin{abstract}
The OBEDUC Program of CAPES has as goal to foment studies and research in education which use the universities available infrastructure and INEP data base. It has as aims to provide the articulation among graduation, under graduation and schools, to stimulate the academic production and the graduate resources, master and doctoral studies. In this sense, we discuss in our paper the questionnaires application results, which we report impacts of the collaborative research work on the education of the two of eight under graduate students and on the professional development of the two of the eight Mathematics teachers inserted
\end{abstract}




\section{autêntica}

in the OBEDUC Network Project Edital 2012 Core UEPB from the last three years. It was a unique and enriched experience to the pre service and in service teachers to have the active insertion opportunity in a project involving education research. The results make sure the vital importance of the governmental support for financial resources of activities on teacher pre professional and professional development, as financial resources of research activities. We can strongly state that the implementation of the OBEDUC Program by CAPES provokes and problematizes new ways in the teacher and researcher education politics in our country by providing interaction and work in a joint way, by integrating under graduate students, graduate students and in service teachers in the same project, in the same process, with the same aim. We believe that the OBEDUC Program by CAPES is, and it can be understood, a study area for education politics for university education in our country, as for the under graduate and graduate level, as for the teacher professional development.

\section{KEYWORDS}

OBEDUC; Mathematics Education; Research; Professional Development; Teacher Education. 


\section{autêntica}

\section{PROGRAMA OBSERVATÓRIO DA EDUCAÇÃO - OBEDUC/CAPES}

Pensando na importância da formação do professor enquanto formação inicial e desenvolvimento profissional para escolas públicas em termos de políticas governamentais, iniciou-se o Programa Observatório da Educação - OBEDUC. Tal Programa foi constituído pelo Decreto Presidencial n 5.803, em 08 de junho de 2006, como resultado de parceria entre Coordenação/CAPES de Melhoramento de Recurso Humano à Nível Universitário e INEP Instituto Nacional de Estudos Pesquisas Educacionais Anísio Teixeira. O Programa OBEDUC objetiva dar suporte ao trabalho acadêmico e prover recursos para estudantes de mestrado e doutorado com auxílio financeiro específico, sendo um deles bolsa de estudos. Outro aspecto, extremamente relevante e inovador, do Programa OBEDUC/CAPES é o de unir estudantes de graduação e pós-graduação com professores da educação básica em exercício, para juntos realizarem pesquisas no campo da educação.

A meta do Programa OBEDUC/CAPES é o de fomentar estudos e pesquisas em educação que utilizem a infraestrutura disponível das Instituições de Educação Superior - IES - e as bases de dados existentes no INEP. Tem como objetivos proporcionar a articulação entre pós-graduação, licenciaturas e escolas de educação básica, estimular a produção acadêmica e a formação de recursos pós-graduados, em nível de mestrado e doutorado.

As modalidades do Programa OBEDUC/CAPES são de núcleos locais compostos por pelo menos um PPG stricto sensu de uma IES e núcleos em rede compostos por pelo menos três PPGs stricto sensu de IES distintas, sendo este o caso de nosso Projeto OBEDUC. As modalidades de bolsas de estudo do Programa OBEDUC/CAPES são: categoria graduando - para estudantes de licenciatura: $R \$ 400,00$ (quatrocentos reais); categoria professor da educação básica - para professores de escolas públicas e privadas de educação básica: $\mathrm{R} \$ 765,00$ (setecentos e sessenta e cinco reais); categoria mestrando-para estudantes de mestrado da IES: $R \$ 1.500,00$ (um mil e quinhentos reais); categoria doutorando - para estudantes de doutorado da IES: $\mathrm{R} \$ 2.100,00$ (dois mil e cem reais); categoria coordenador de núcleo e geral - para o docente doutor da IES: $\mathrm{R} \$ 1.500,00$ (um mil e quinhentos reais). As bolsas de estudo são financiadas pela CAPES diretamente aos bolsistas por meio de crédito bancário.

\section{UM PROJETO OBSERVATÓRIO DA EDUCAÇÃO OBEDUC EM REDE}

Nosso projeto de pesquisa colaborativo em rede, Trabalho colaborativo com professores que ensinam Matemática na Educação Básica em escolas públicas das regiões Nordeste e Centro-Oeste, foi aprovado pelo Programa Observatório da Educação OBEDUC/CAPES Edital 2012, período de três anos, entre março 2013 e março 2016, com orçamento de $\mathrm{R} \$ 1.600 .000,00$ (um milhão e seiscentos mil reais) entre bolsas de estudo, material de custeio e capital, tem como universidades parceiras a Universidade Federal do Mato Grosso do Sul (UFMS) núcleo geral e local, tendo Dra. Patricia Sandalo Pereira como coordenadora geral e de núcleo; a Universidade Estadual da Paraíba (UEPB) núcleo local, tendo Dra. Abigail Fregni Lins como coordenadora de núcleo; e Universidade Federal de Alagoas (UFAL) núcleo local, tendo Dra. Mercedes Carvalho como coordenadora de núcleo.

Objetivamos em nosso projeto estudar, pesquisar e desenvolver, de forma colaborativa, alternativas didáticas e metodológicas a serem trabalhadas em salas de aula de Matemática do Ensino Fundamental I ao Ensino Médio em escolas públicas nas regiões Nordeste e Centro-Oeste. As alternativas didáticas e metodológicas envolvem uso de aparatos como tablets (Fundamental I), materiais manipuláveis, calculadoras, robótica (Fundamental II) e GeoGebra (Ensino Médio). Nosso projeto visou colaboração entre três as pesquisadoras 


\section{DOCENTE}

\section{autêntica}

educadoras matemáticas, doutorandos e mestrandos em Educação Matemática, professores polivalentes e de Matemática da educação básica (Fundamental I e II, Ensino Médio) e graduandos de Cursos de Pedagogia e Licenciatura Plena em Matemática (Formação de Professores) dos Estados de MS, PB e AL.

As três pesquisadoras educadoras matemáticas, estudantes de doutorado e mestrado em Educação Matemática, professores de Matemática e de Pedagogia em exercício e em formação formam os 46 membros de nosso projeto de pesquisa colaborativo em rede:

\begin{tabular}{|c|c|c|c|c|}
\hline Universidades & UFMS & UEPB & UFAL & TOTAL \\
\hline Coordenadores & 01 & 01 & 01 & 03 \\
\hline Estudantes de Mestrado & 04 & 04 & 01 & 09 \\
\hline Estudantes de Doutorado & --- & --- & 01 & 01 \\
\hline Professores em exercício & 07 & 08 & 03 & 18 \\
\hline Professores em formação & 04 & 08 & 03 & 15 \\
\hline TOTAL & 16 & 21 & 09 & 46 \\
\hline
\end{tabular}

Tabela 1 - Distribuição dos Membros do Projeto OBEDUC em rede UFMS/UEPB/UFAL

Na Universidade Federal UFMS, coordenação geral e de núcleo, o grupo é formado por 16 membros, estudantes de mestrado e doutorado em Educação Matemática, professores de Matemática em formação e em exercício, que pesquisam/trabalham sobre formação inicial de professores (roda de conversa) e formação continuada de professores (roda de conversa). Na Universidade Estadual UEPB, coordenação de núcleo, o grupo é formado por 20 membros, divididos em 4 equipes, cada delas composta de um estudante de mestrado em Educação Matemática, dois professores de Matemática em formação e dois professores de Matemática em exercício. Cada equipe com sua própria pesquisa/trabalho: Calculadoras e Argumentação Matemática; Robótica e Educação Matemática; Prova e Demonstração Matemática e GeoGebra; e Deficiência Visual e Materiais Manipuláveis na Educação Matemática. Na Universidade Federal UFAL, coordenação de núcleo, o grupo é formado por 9 membros, estudantes de mestrado e doutorado em Educação Matemática, professores de Pedagogia e Matemática em formação e em exercício, diretora e coordenadora pedagógica, com pesquisa/trabalho sobre o uso de tablets para a Matemática nos anos iniciais e gestão escolar - Ensino Fundamental I e II (interação entre Pedagogos e professores de Matemática).

Organizamos os três anos de nosso projeto de pesquisa colaborativo em três etapas: 


\section{autêntica}

Ano 2013: estudos, leituras, debates sobre trabalhos científicos (teses e dissertações), teorias e autores; ano 2014: criação e elaboração de propostas didáticas; ano 2015: aplicação das propostas didáticas e análise. Reuniões gerais e de equipe semanais (2 a 4 horas) ao longo dos anos de 2013, 2014 e 2015. Sendo o ano de 2016 dedicados às defesas, fechamentos e publicações.

\section{FORMAÇÃO DO FUTURO PROFESSOR E PESQUISADOR}

Nossa educação superior brasileira não deveria se limitar a formar professores para dominar conteúdos somente, e sim formá-los a pensar, refletir, propor soluções, problemas, trabalhar e colaborar uns com outros. Como ressalta a UNESCO, a escola, em nosso caso a universidade, deve favorecer a formação de seres críticos e participativos, conscientes de seu papel nas mudanças sociais. Além destes, saber pesquisar, selecionar e hierarquizar informações para construção de conhecimento tornou-se necessidade na atual sociedade tecnológica, como enfatiza Lévy (1999). Por sua vez, Bachelard (1996) cunhou o termo espírito científico como característica do ser apto a construir o conhecimento científico.

Em nossas universidades brasileiras, em diversas áreas do conhecimento, a iniciação científica é desenvolvida por alunos de graduação. Em geral, os alunos que se dedicam a esta atividade possuem pouca ou nenhuma experiência em trabalhos de pesquisa científica, sendo acompanhados por seus orientadores. Durante a $5^{a}$ Reunião de Trabalho com Pró-Reitores de Pesquisa e Coordenadores do PIBIC/PIBIC-Af/PIBIT, no auditório do CNPq, em Brasília, entre 21 e 22 de outubro de 2014, o Presidente Glaucius Oliva ressaltou que a iniciação científica possui contribuições marcantes para o desenvolvimento nacional ao longo da história. Já o Diretor de Cooperação Institucional (DCOI/CNPq), Paulo Sergio Lacerda Beirão, destacou que o Programa Institucional de Bolsas de Iniciação Científica (PIBIC) foi responsável pela consolidação da ciência brasileira e continua sendo o fio condutor de todo sistema nacional de ciência e tecnologia. Acrescentou a importância da perspectiva de que precisamos formar pessoas, com qualificação e formação, capazes de desenvolver pesquisa para o nosso país.

O que nos faz entender, e concluir, que de fato não basta formarmos nossos professores brasileiros apenas com relação ao domínio de conteúdos em que área seja de conhecimento, como geralmente ainda ocorre em nossos cursos superiores, mas sim formarmos professores pesquisadores, professores críticos, pensantes e autônomos.

\section{DESENVOLVIMENTO PROFISSIONAL DO PROFESSOR E PESQUISADOR}

Para Lüdke (2006), a prática da pesquisa dá mais recurso ao professor para questionar sua prática, levando-o a uma profissionalidade autônoma e responsável. A conceber pesquisa como forma de entendimento sobre o que faz, por que faz e a descobrir novas maneiras de produzir conhecimento.

Infelizmente, é sabido que o isolamento de nossos professores se dá, em primeira instância, pela arquitetura e organização escolar, pela distribuição de tempo e espaço, e pelo distanciamento, isto é, pela falta de interação entre os professores. O isolamento profissional como norma e cultura pode ser vantajoso ou não para os professores. Bird e Little (1986) ressaltam que embora o isolamento profissional facilite a criatividade individual dos professores, e os libere de dificuldades associadas com o trabalho compartilhado, colaborativo, os limita de progredir ao longo da carreira. 


\section{autêntica}

Além do isolamento profissional, é sabido sobre a falta de autonomia profissional, provavelmente devido à forma como nossos professores são formados. Adquirir autonomia profissional faz com que o professor se torne menos alienado e mais crítico em relação a si e a outros, buscando novas formas de se desenvolver profissionalmente.

Entendemos que o fazer pesquisa e o trabalhar de forma colaborativa podem ser modos de combate ao isolamento profissional e a falta de autonomia profissional de nossos professores. Como destaca Imbernón (2006, p. 20), "uma maneira de revitalizar profissionalmente o professor é a geração de processos de aprimoramento profissional coletivo, adotando inovações e dinâmicas de mudança nas instituições educativas" (grifo nosso). Afirma ainda Imbernón ser o professor um:

agente dinâmico cultural, social e curricular, capaz de tomar decisões educativas, éticas e morais, de desenvolver o currículo em um contexto determinado e de elaborar projetos e materiais curriculares com a colaboração dos colegas, situando o processo em um contexto específico controlado pelo próprio coletivo (IMBERNÓN, 2006, p. 21, grifo nosso).

Já Wagner (1997, p. 16) cunhou o termo coaprendizagem em relação ao trabalho entre pesquisadores e professores:

Em um acordo de coaprendizagem, pesquisadores e professores são ambos participantes no processo de educação e sistemas escolares. Ambos estão engajados em ação e reflexão. Por trabalharem juntos, cada um aprende algo sobre o mundo do outro. De igual importância, porém, cada um talvez aprenda algo mais sobre seu próprio mundo e suas conexões com as instituições e escolas (grifo nosso).

E Cochran-Smith e Lytle (1999) chamam de conhecimento da prática o desenvolvimento de pesquisa de forma colaborativa, em grupo ou em redes de trabalho. Acrescentam que o conhecimento se constrói coletivamente, formado por professores trabalhando em projetos de desenvolvimento na escola, de formação ou de pesquisa colaborativa.

\section{TRABALHO COLABORATIVO E DE PESQUISA EM NOSSO PROJETO OBEDUC EM REDE}

Peixoto e Carvalho (2007) afirmam que a principal diferença entre trabalho cooperativo e colaborativo está no nível da autonomia de cada participante e no controle sobre ações dele ou dela no grupo. Isto é, optar por cooperação ou colaboração dependerá da maturidade dos participantes, de suas autonomias e de suas competências sobre o tema a ser trabalhado ou proposto. De acordo com Peixoto e Carvalho, se nós optarmos por um trabalho colaborativo e iniciar uma tarefa específica, o desenvolvimento da autonomia e a capacidade de trabalhar em grupo será a mesma meta que em uma abordagem cooperativa. Porém, a diferença é que a colaboração dá maior liberdade para os participantes. Já, de acordo com Ibiapina (2008), em um trabalho de pesquisa colaborativo os professores trabalham interagindo com os pesquisadores, desenvolvendo teorias sobre suas práticas. Isto é, em um trabalho de pesquisa colaborativo os participantes são considerados copesquisadores e, neste processo, a colaboração ocorre no estabelecimento de interações entre as múltiplas competências de cada participante: os professores com sua potencial análise de práticas pedagógicas e os pesquisadores com o potencial organizacional dos passos de pesquisa. A interação entre estes potenciais representa a qualidade da colaboração, com pouca opressão e relação forte engrandece o potencial de colaboração. Neste sentido, o trabalho de pesquisa colaborativo, de acordo com Ibiapina, provê condições para os professores refletirem sobre suas práticas e sobre seus valores e crenças, fazendo 


\section{autêntica}

que questionem os aspectos do seu trabalho profissional. Em síntese, para a autora, esta é uma prática alternativa de questionar a realidade educacional, na qual pesquisadores e professores trabalham juntos na implementação de mudanças e na solução de problemas compartilhando responsabilidade na tomada de decisões e no fazer pesquisa.

Ainda, de acordo com Ibiapina, a ideia de colaboração entre pesquisadores e professores ao desenvolver conhecimento sobre prática de ensino vem da sabida distância entre o mundo da pesquisa e a prática profissional. Desta forma, para pesquisar de modo colaborativo é investigar um assunto de pesquisa proposto pelo pesquisador, mas que motiva o professor a repensar sua prática, se for o caso, mudá-la.

Seguimos o pensamento de Ibiapina em nosso projeto de pesquisa colaborativo em rede OBEDUC UFMS/ UEPB/UFAL, pois nossa ideia principal era o de alcançar, a partir de uma abordagem colaborativa, coprodução de conhecimento, pesquisa interativa, formação de professores, reflexão e desenvolvimento profissional dos 46 membros do projeto.

Nós entendemos que o trabalho de pesquisa colaborativo envolve movimentos complexos; leva tempo a entender por sua realização envolver opções de ações formativas a auxiliar os membros do projeto a valorizar o pensamento e a construção de um ambiente discursivo, de autonomia, e de mútuo respeito. Com isso, "o processo de aprendizagem construído de modo colaborativo oferece potencial ajuda para o pensamento teórico e prático, assim como fortalece o ensino, abre formas para o desenvolvimento profissional e pessoal para os pesquisadores e para os professores" (IBIAPINA, 2008, p. 31).

Além de Ibiapina, seguimos as linhas de pensamento de Jaworski (2008) e de Fullan e Hargreaves (2000). Jaworski enfatiza o desgarro que necessitamos enfrentar com relação ao aspecto hierárquico quando se desenvolve pesquisa ou trabalhos de pesquisa com professores de Matemática. Enfatiza que para podermos estabelecer um diálogo frutífero e construtivo entre acadêmicos educadores matemáticos, formadores de professores de Matemática e professores de Matemática em exercício, é necessário dar-se voz a todos, de forma igualitária, e que a todos seja provida a noção de igual pertença ao longo do processo. Fullan e Hargreaves também enfatizam estes aspectos, de forma geral, a todos os profissionais da educação, em especial a possibilidade e necessidade de se estabelecer ambientes colaborativos nas escolas.

\section{IMPACTO DO TRABALHO COLABORATIVO E DA PESQUISA EM NOSSO PROJETO OBEDUC}

Em outras instâncias discutimos sobre a metodologia do trabalho colaborativo e de pesquisa de nosso Projeto OBEDUC em rede (LINS, PEREIRA e CARVALHO, 2016a) e sobre o impacto primeiro dos professores da educação básica membros de nosso Projeto logo após realização do I Seminário Anual OBEDUC ao final do ano de 2013 (LINS, PEREIRA e CARVALHO, 2016b).

Neste artigo focamos na discussão sobre o impacto do trabalho colaborativo e de pesquisa em nosso Projeto OBEDUC em rede na formação e no desenvolvimento profissional dos professores de Matemática membros do Projeto, especificamente do Núcleo UEPB. Mais precisamente, o impacto de nosso Projeto OBEDUC Núcleo UEPB sobre isolamento pré-profissional e profissional e a falta de autonomia pré-profissional e profissional de nossos professores de Matemática em formação e em exercício.

Como citado anteriormente, a primeira etapa de nosso Projeto OBEDUC em rede foi de estudos; a segunda de elaboração de propostas didáticas; e a terceira de aplicação das propostas didáticas em escolas. 
Ao final da terceira etapa de nosso Projeto, no ano de 2015, aplicamos questionário a todos os membros bolsistas do Núcleo UEPB, isto é, a todos os 8 licenciandos em Matemática (categoria graduando), aos 8 professores de Matemática da educação básica (categoria professor) e aos 4 mestrandos em Educação Matemática (categoria mestrando).

Neste artigo centramos nas respostas dos questionários, relatos, de 2 dos 8 graduandos licenciandos em Matemática e de 2 dos 8 professores de Matemática da educação básica entre as 4 Equipes do Núcleo UEPB, sendo os graduandos licenciandos bolsistas Valbene da Equipe Deficiência Visual e Materiais Manipuláveis na Educação Matemática e Helder da Equipe Prova e Demonstração Matemática e GeoGebra, e os professores de Matemática da educação básica bolsistas Alane da Equipe Calculadoras e Argumentação Matemática e Genailson da Equipe Robótica e Educação Matemática.

\section{PROFESSORES DE MATEMÁTICA EM FORMAÇÃO}

O questionário foi estruturado em quatro partes, denominadas Fase I - Estudos; Fase II - Proposta Didática; Fase III - Aplicação da Proposta Didática; e, Fase IV - Resultados. Sobre Fase I - Estudos, solicitamos:

A primeira fase de nosso Projeto Colaborativo OBEDUC foi de reuniões, estudos, leituras, debates, discussões e I Seminário OBEDUC. Descreva as dificuldades encontradas por você nesta fase de início do trabalho e da pesquisa em equipe. Descreva suas descobertas, aprendizados.

A graduanda licencianda em Matemática Valbene dissertou:

Penso que a única dificuldade que tive foi no início do projeto, pois tive que separar um pouco os estudos da graduação com as leituras do projeto, mas aos poucos foi tudo se ajeitando e deu tudo certo. Participar do projeto foi algo que me trouxe bastante aprendizado e consciência de um assunto que eu ainda não tinha ouvido falar, a inclusão, e foi também onde eu comecei a me adaptar à leitura, algo que para mim era horrível. A colaboração foi algo que ajudou muito em nossas reuniões, pois fez com que todos nós expressássemos nossas opiniões de forma igualitária, sempre chegando a um consenso (grifo nosso).

O graduando licenciando em Matemática Helder dissertou:

Uma das grandes dificuldades que eu encontrei no início do projeto foi me adaptar à rotina de pesquisador, pois como entrei no projeto ainda muito "jovem" no curso de Licenciatura em Matemática, não tinha tido este contato com a pesquisa, ou seja, tive que me adaptar à rotina de leituras, pesquisas, etc. Quando eu conheci a Equipe Prova e Demonstração Matemática e GeoGebra fiquei com certo anseio, pois iria trabalhar junto com 1 mestrando e 2 professores da escola básica, evidentemente mais experientes do que eu no âmbito da pesquisa. Fiquei com medo de ser deixado para trás, mas o que me confortou foi em saber que iríamos trabalhar de forma colaborativa, que todos tinham voz, sem hierarquia. Começamos então as leituras e debates sobre nossa pesquisa. Debates sempre muito ricos e de enorme importância para minha formação como professor de Matemática (grifo nosso).

Para os graduandos Valbene e Helder, futuros professores de Matemática, a maior descoberta e aprendizado que parece ter sido a eles durante a Fase I de nosso Projeto OBEDUC foi a possibilidade real de se trabalhar de forma colaborativa, e que de fato é possível formar uma equipe, um grupo de pessoas, na qual 


\section{autêntica}

a interação se dá de forma igualitária (JAWORSKI, 2008), sem que haja um líder, chefe, ou até mesmo hierarquia na equipe, possivelmente a oprimir os que estejam ainda em formação, como no caso de Valbene e Helder. Valbene em seu relato ressalta a dificuldade já sabida por ela com relação ao ato de leitura, nos remetendo à formação que provemos aos futuros professores em nossos cursos de licenciaturas, longe do que UNESCO prega e clama. Chama nossa atenção Helder, que em seu relato aponta a dificuldade em se adaptar à rotina de pesquisador, nos levando à Bachelard (1996) quando enfatiza a importância da formação do espírito científico, assim como Paulo Sérgio Lacerda Beirão ao se referir sobre a importância do Programa de Iniciação Científica do CNPq.

Sobre Fase II - Proposta Didática, solicitamos:

A segunda fase de nosso Projeto Colaborativo OBEDUC foi de reuniões, leituras, debates, discussões, planejamento de uma proposta didática e II Seminário OBEDUC. Descreva as dificuldades encontradas por você nesta fase do trabalho e da pesquisa em equipe. Descreva suas descobertas, aprendizados.

A graduanda licencianda em Matemática Valbene dissertou:

Essa fase foi a mais trabalhosa, pois foi onde começamos a pensar qual série iríamos trabalhar, que assuntos iríamos abordar, quais os materiais que precisávamos para realizar as atividades que iríamos propor, entre outras coisas. Foi também onde cada membro da equipe começou a pesquisar mais sobre os assuntos eu iríamos trabalhar e fomos vendo quais se encaixavam e quais não iriam ser possíveis ser feito a realização. Passamos quase um ano lendo sobre os assuntos que tínhamos escolhido, sempre debatendo sobre o que cada um achava sobre seu tema, mas chegamos ao fim de algumas leituras e percebemos que iríamos trabalhar com materiais diferentes dos que já havíamos escolhido. Com isso, começamos novamente a discutir sobre os materiais até encontrarmos os que fossem precisos para realização do que tínhamos em mente (grifo nosso).

O graduando licenciando em Matemática Helder dissertou:

Nesta fase do projeto o maior desafio foi concluir nossas ideias para elaborarmos a proposta didática, pois seria dela que iríamos coletar os dados para nossa pesquisa como um todo, assim como para nossas pesquisas individuais. De início havia muitas ideias para agregarmos na proposta, porém de certa forma diversas, não conseguimos encaixar nossas ideias, mas como trabalhamos de maneira colaborativa, conseguimos reverter esta situação e unir as ideias individuais para formar uma proposta só, que supria nossas necessidades como pesquisadores como também acreditamos que supria as necessidades dos alunos sobre o tema em questão (grifo nosso).

Nos relatos de Valbene e Helder é interessante, relevante e importante notar as descrições sobre o processo que passaram enquanto professores e pesquisadores em formação. Percebe-se que Helder na Fase II já se considerava um pesquisador, e capaz de descrever o processo de reformulação, de forma colaborativa da equipe, sobre a proposta didática que estariam a elaborar (LÜDKE, 2006). Descreve o vai e vem de uma pesquisa, o voltar às leituras, o discutir novamente as ideias individuais e coletivas, o redefinir caminhos, apontando a formação do espírito científico ressaltado por Bachelard (1996). Além dos processos de pesquisa de Valbene e Helder, Helder demonstra preocupação com o ensino, preocupação em que o material que a equipe estava desenvolvendo com base em pesquisa, a proposta didática, fosse também algo frutífero aos 
alunos, às necessidades dos alunos. Valbene e Helder são professores em formação já em reflexão sobre o trabalho em sala de aula, sobre o conhecimento na prática, como ressaltam Cochran-Smith e Lytle (1999).

Sobre Fase III - Aplicação da Proposta Didática, solicitamos:

A terceira fase de nosso Projeto Colaborativo OBEDUC foi de reuniões, finalização e aplicação de uma proposta didática em escolas, e agendamento do III Seminário OBEDUC. Descreva as dificuldades encontradas por você nesta fase do trabalho e da pesquisa em equipe. Descreva suas descobertas, aprendizados.

A graduanda licencianda em Matemática Valbene dissertou:

Nesta fase começamos a pensar nas atividades que iríamos trabalhar. Com a série e os materiais já definidos, começamos então a discutir as atividades que estávamos elaborando juntamente com a elaboração do questionário. Foi também onde decidimos quando se daria a proposta, em qual escola iria ser realizada e quantos alunos iriam participar e se iria ser em dupla ou individual. Apesar de ter demorado a realização da proposta em vista de greves e disponibilidade dos alunos deficientes visuais, pois eles não se intimidam com os obstáculos e são bastante inteligentes. No início pensei que eles não iriam saber responder as atividades da proposta, mas ao entregar o questionário fui mudando de ideia e discordando totalmente do meu primeiro pensamento. Aconteceu justamente o oposto que eu pensava, os alunos sabiam basicamente tudo que se pedia na proposta, sem ter muitas dúvidas ou dificuldades em responder, ou seja, subestimamos a capacidade que eles possuem. E também o tempo não foi favorável para nós, pois não deu para realizar totalmente a proposta (grifo nosso).

O graduando licenciando em Matemática Helder dissertou:

Nesta fase já estávamos um pouco mais tranquilos bastante entrosados. Chegava a hora de irmos a campo botar em prática o que havíamos estudado e debatido muito com relação à aplicação da proposta em si. Não senti muita dificuldade, a dificuldade existente foi apenas de lidar com os alunos como sujeito pesquisado, pois como se trata de uma proposta didática, os alunos queriam tirar dúvidas e faziam perguntas constantemente e eu como pesquisador não podia intervir da forma que eles queriam, pois iria induzir o aluno (grifo nosso).

Valbene e Helder descrevem como dificuldade durante a Fase III o iniciar a pesquisa de campo, isto é, a ida às escolas públicas e definição de datas a aplicar a proposta didática aos alunos. Extremamente interessante o relato de Valbene sobre seu primeiro pensamento (crença), que alunos com deficiência visual teriam maior dificuldade com a proposta didática e com a Matemática, não condizia com a que ela verificou na prática, em sua pesquisa de campo (LÜDKE, 2006). Relato este de uma professora e pesquisadora em formação, a assumir que seus pensamentos primeiros (crenças e concepções) eram errôneos. Algo precioso e mais uma vez nos mostrando a importância desses professores em formação estarem passando por um processo de pesquisa, no qual descobertas e aprendizados ocorrem. Helder relata preocupação, estando em sala de aula como professor daqueles alunos e em ter o cuidado de não intervir no que os alunos o solicitavam para que não houvesse problemas no resultado do que estavam a responder, já que todo aquele material, proposta didática, era de cunho investigativo, de pesquisa, a ser analisado. Mais uma vez demonstrando a formação do espírito cientifico ocorrendo a esses professores em formação, a ciência, o saber diferenciar entre situação de docência e de pesquisa, sinalizando um processo de coaprendizagem, como ressalta Wagner (1997). 


\section{autêntica}

Sobre Fase IV - Resultados, solicitamos:

A quarta fase de nosso Projeto Colaborativo OBEDUC será de reuniões, leituras, discussões, análises e escritas do trabalho realizado e dos resultados alcançados. Descreva as dificuldades que acredita poder encontrar nesta fase do trabalho e da pesquisa em equipe. Descreva suas possíveis descobertas, aprendizados.

Descreva, da melhor forma possível, o que foi para você ter feito parte deste Projeto Colaborativo OBEDUC.

A graduanda licencianda em Matemática Valbene dissertou:

Acredito que não vamos encontrar muitas dificuldades nessa etapa. Vamos analisar os dados e encontrar referências para que possamos nos basear e que adequem com a nossa pesquisa.

Foi uma experiência enriquecedora para mim, pois mostrou um mundo ao qual ainda não tinha conhecimento e me fez perceber o quanto é importante ter uma formação em que possamos lidar em qualquer situação que encontramos na sala de aula, assim como procurar meios que auxiliem na aprendizagem dos alunos. Me fez perceber como é importante a questão da leitura e de ter compromisso com o que fazemos (grifo nosso).

O graduando licenciando em Matemática Helder dissertou:

Acredito que irei enfrentar problemas que já aconteceram antes, que será em organizar nossas escritas de tal forma a torna-se apenas uma, mas como já passamos por situações parecidas, iremos com certeza vencer mais esta etapa, com dedicação e trabalho em equipe.

Ter feito parte do projeto OBEDUC para mim foi um marco ímpar. Além de poder contribuir para minha formação como licenciando em Matemática, pude botar em prática o que eu tanto desejava quando entrei no Curso de Matemática, que era contribuir de alguma forma para melhorar o ensino e a aprendizagem da Matemática em nosso país. Participar do OBEDUC foi, além de tudo, uma experiência de vida (grifo nosso).

Sobre descobertas e aprendizados, o relato de Valbene deixa claro o quanto relevante e crucial foi a ela estar inserida por três anos em estudos e pesquisa no Projeto OBEDUC, o quanto a fez crescer como pesquisadora e professora. Uma professora ainda em formação, de que ao participar do Projeto OBEDUC a fez perceber a importância de leitura, inicialmente, na Fase I, de seu receio. Em especial o compromisso com o que fazemos, como relata Valbene, nos mostra a consciência profissional alcançada por Valbene (LÜDKE, 2006) em participar de um projeto de natureza como do OBEDUC. Helder relata a volta de seu receio na Fase IV ao enfrentar o processo de escrita, mas logo relata que o mesmo será rapidamente superado por conta do trabalho colaborativo, por estarem trabalhando em conjunto (IBIAPINA, 2008). Além destes, por muitas vezes, não nos damos conta, como formadores de professores, em termos em nossas mãos alunos no curso de Licenciatura com o propósito, meta e desejo de, de fato, contribuir com o ensino e aprendizagem de nosso país, como relata Helder.

\section{PROFESSORES DE MATEMÁTICA EM EXERCÍCIO}


Lembrando, o questionário foi dividido em quatro partes, sendo elas, Fase I - Estudos; Fase II - Proposta Didática; Fase III - Aplicação da Proposta Didática; e, Fase IV - Resultados. Sobre Fase I - Estudos, solicitamos:

A primeira fase de nosso Projeto Colaborativo OBEDUC foi de reuniões, estudos, leituras, debates, discussões e I Seminário OBEDUC. Descreva as dificuldades encontradas por você nesta fase de início do trabalho e da pesquisa em equipe. Descreva suas descobertas, aprendizados.

A professora de Matemática Alane dissertou:

Essa primeira fase foi de muitas descobertas e aprendizado. Durante a licenciatura não participei de projetos, dessa forma senti muita dificuldade de trabalhar em equipe e também como não participei de seminários e congressos, entre outros eventos oferecidos pelas Instituições de Ensino Superior, senti muita dificuldade em escrita de trabalhos acadêmicos, mesmo já tendo finalizado o TCC e monografia da Especialização. Como nessa fase do projeto houve muitos estudos, leituras, debates e discussões, as habilidades foram melhoradas e aperfeiçoadas. O I Seminário OBEDUC foi de muito aprendizado, além de ser o momento de socialização das equipes dos três núcleos, de tudo que foi trabalhado nesta primeira fase, tive a oportunidade de conhecer a UFAL, juntamente com todos os colegas do grupo (grifo nosso)

O professor de Matemática Genailson dissertou:

A maior dificuldade encontrada nesta etapa foi voltar aos estudos, principalmente a leitura e a escrita. Devido ao fato de lecionar há muito tempo, considerava que tinha um bom conhecimento no processo ensino/aprendizagem, porém o trabalho colaborativo me fez repensar algumas práticas do dia a dia em sala de aula (grifo nosso).

Alane, professora de Matemática em exercício, relata como dificuldade sua falta de experiência quando ainda em formação com relação à leitura, debates, o ato de pesquisar e o frequentar eventos científicos, apesar da realização de seu trabalho monográfico de finalização de curso e de especialização, o que nos faz refletir a forma como trabalhamos com nossos alunos futuros professores quando chegada a hora deles se debruçarem em algum assunto específico, estudar sobre o mesmo e redigir a respeito (BACHELARD, 1996; LÉVY, 1999). Parece ser a inserção de Alane no Projeto OBEDUC o primeiro momento, primeira oportunidade de pesquisa em educação à Alane, mesmo tendo realizado seus trabalhos de conclusão de curso e especialização. Genailson, em seu relato com relação às dificuldades, descreve o que sabemos ocorrer: professores formados, em exercício, não mais estudam, não mais se engajam, ou não são engajados em novos estudos, em especial sobre sua própria prática pedagógica (IBIAPINA, 2008). Genailson relata como descoberta e aprendizado o quanto acreditava estar pronto com relação ao seu conhecimento matemático, didático e pedagógico anterior à sua inserção no Projeto OBEDUC, que o fez perceber que havia muito a aprender, e que aprendeu, a ponto de fazê-lo refletir sobre sua própria prática e iniciar um processo de mudança (IMBERNÓN, 2006). Todo processo ocorrido à Alane e Genailson se deu apenas durante o primeiro ano do Projeto OBEDUC, o que nos faz perceber o retrato do isolamento profissional o qual Alane e Genailson sofrem em seus ambientes de trabalho, nas escolas (FULLAN e HARGREAVES, 2000). O quanto nossas escolas não proporcionam um ambiente de crescimento aos nossos professores, aos profissionais que ali exercem seus ensinamentos. Outra dificuldade apontada por Alane em seu relato foi o de trabalhar em equipe, o que também sinaliza os efeitos do isolamento profissional, como também pré-profissional (quando em formação), pois Alane relata que nem durante a formação dela como profissional, quanto em exercício, passou por algum processo de trabalho colaborativo, em equipe, algo feito de forma coletiva, com trocas de ideias e experiências (BIRD e LITTLE, 1986). 


\section{autêntica}

Sobre Fase II - Proposta Didática, solicitamos:

A segunda fase de nosso Projeto Colaborativo OBEDUC foi de reuniões, leituras, debates, discussões, planejamento de uma proposta didática e II Seminário OBEDUC. Descreva as dificuldades encontradas por você nesta fase do trabalho e da pesquisa em equipe. Descreva suas descobertas, aprendizados.

A professora de Matemática Alane dissertou:

Nessa segunda fase as dificuldades de se trabalhar em grupo foram amenizadas, além de ter também uma melhora significativa na participação das discussões e debates a partir das leituras realizadas. O planejamento da proposta didática foi bastante discutida até chegarmos a um objetivo comum quanto definição da escola, qual/quais turmas, quais conteúdos deveriam ser explorados, quais tipos de problemas e também o tipo de organização dos alunos na execução da proposta (individual, duplas, grupos). O II Seminário, realizado em Campina Grande, foi bastante produtivo, já que com as apresentações das pesquisas bem encaminhadas, ficou mais claro para todos o que cada equipe e também cada membro da equipe iria abranger como objeto de pesquisa, seu olhar individual (grifo nosso).

O professor de Matemática Genailson dissertou:

Neste momento houve um "conflito" maior de ideias, duelavam em nossas mentes o teórico e o prático, o possível e o utópico, a prática da escola e as novas propostas. O maior ganho neste período foi constatar que é possível de trabalhar com vários educadores em níveis diferentes, a ponto de elaborar uma proposta didática, visto sobre o prisma de vários autores e ao mesmo tempo personagens com saberes e vivências com uma diversidade tão antagônica. $O$ trabalho colaborativo proporcionou uma aprendizagem compartilhada, todos aprenderam e aprenderam muito, talvez a maior delas foi perceber que o processo ensino/aprendizagem não precisa ser bidirecional, mas pode ser multidirecional, pois no fim todos ganham, principalmente o aluno (grifo nosso).

Alane em seu relato descreve como descoberta e aprendizado sua superação durante a Fase II do Projeto OBEDUC de trabalhar em conjunto, de forma colaborativa. O interessante é notar no relato de Alane a não perda de individualidade no processo de colaboração. Mesmo estando tudo junto e misturado, Alane percebeu seu crescimento individual no coletivo, em especial com relação ao processo de pesquisa, do pesquisar (PEIXOTO e CARVALHO, 2007; JAWORSKI, 2008). O relato de Genailson sobre descobertas e aprendizado durante a Fase II é extremamente revelador. Enquanto Genailson na Fase I se sentia afastado dos estudos, de debates, de pensares, na Fase II do Projeto OBEDUC descreve seu processo de revolução profissional, assim como dos membros de sua equipe (LÜDKE, 2006). Genailson relata a saúde de estarem todos eles, em estágios distintos de formação, de forma colaborativa engajados em um processo de crescimento pessoal e profissional (COCHRAN-SMITH e LYTLE, 1999).

Sobre Fase III - Aplicação da Proposta Didática, solicitamos:

A terceira fase de nosso Projeto Colaborativo OBEDUC foi de reuniões, finalização e aplicação de uma proposta didática em escolas, e agendamento do III Seminário OBEDUC. Descreva as dificuldades encontradas por você nesta fase do trabalho e da pesquisa em equipe. Descreva suas descobertas, aprendizados.

A professora de Matemática Alane dissertou: 


\title{
autêntica
}

\begin{abstract}
Ao finalizarmos a proposta didática, as reuniões foram mais tranquilas e partimos para a aplicação da proposta. Houve um pouco de atraso na aplicação devido à greve ocorrida na rede estadual de ensino com duração de um mês. Finalizada a greve, conseguimos aplicar a proposta de acordo com o planejado. Uma das dificuldades encontradas na aplicação da proposta foi o de reunir todos os professores de Matemática da escola para aplicação da redação e questionário. Com isso, essa etapa foi apresentada de forma individual aos professores. Outra dificuldade foi conseguir, ou pelo menos tentar, adequar o tempo da aplicação da proposta com os alunos. Essa fase foi a de maior aprendizado, pois vi no concreto o que já havia visto na teoria quanto ao conhecimento de calculadoras e argumentação (grifo nosso).
\end{abstract}

O professor de Matemática Genailson dissertou:

O maior desafio nesse momento foi redirecionar a logística para aplicação da proposta, visto que trabalhamos com elementos tecnológicos que dependiam uns dos outros. Aprendemos que se desenvolvermos o trabalho em equipe bem pensado e bem planejado teremos frutos que podem superar as nossas expectativas. Essa parte do projeto foi extremamente gratificante, não somente para nós, Equipe Robótica e Educação Matemática, que vimos a concretização de uma fase importante da nossa pesquisa, mas também para os alunos, que se sentiram valorizados e motivados a fazer a proposta dar certo, foram solidários e partícipes em todos os momentos (grifo nosso).

Alane e Genailson apontam como dificuldades na Fase III a aplicação das propostas didáticas devido às greves ocorridas na educação básica pública, reunir todos os professores de Matemática das escolas a responderem questionário e redigirem uma redação, assim como organizar os recursos tecnológicos necessários para aplicação da proposta. Não houve dificuldade a eles o aceite dos gestores das escolas e dos professores a participarem das pesquisas propostas, o que nos mostra a constante presença de disponibilidade das escolas públicas brasileiras para realização de pesquisas em seus ambientes. Sobre descobertas e aprendizados durante a Fase III, interessante Alane relatar que via a pesquisa realizada pôde constatar de fato que o uso de calculadoras na educação matemática, explorando a argumentação matemática é eficaz, confirmando o que havia lido a respeito, ou seja, confirmando na prática a teoria, algo frutífero à formação docente e ao desenvolvimento profissional (WAGNER, 1997; LÜDKE, 2006). O fazer sentido entre teoria e prática é algo fundamental para nós, profissionais da educação. Já Genailson em seu relato enfatiza o quão importante foi a todos eles da equipe terem pensado, planejado e organizado bem a proposta didática e a aplicação da mesma, além de ressaltar o ganho que foi aos alunos a experiência de terem sido envolvidos com a proposta didática. O relato de Genailson nos mostra a importância de tempo e espaço que nós, profissionais da educação, necessitamos para um bom desempenho de nossas docências, o quanto saudável e necessário se faz estarmos, enquanto professores em exercício, educadores, engajados em projetos, de pesquisa ou não, a contribuir com nosso desenvolvimento profissional e consequente melhoria e aprimoramento de nossas docências, de nossas práticas pedagógicas e didáticas (FULLAN e HARGREAVES, 2000; IBIAPINA, 2008).

Sobre Fase IV - Resultados, solicitamos:

A quarta fase de nosso Projeto Colaborativo OBEDUC será de reuniões, leituras, discussões, análises e escritas do trabalho realizado e dos resultados alcançados. Descreva as dificuldades que acredita poder encontrar nesta fase do trabalho e da pesquisa em equipe. Descreva suas possíveis descobertas, aprendizados.

Descreva, da melhor forma possível, o que foi para você ter feito parte deste Projeto Colaborativo OBEDUC. 


\title{
autêntica
}

A professora de Matemática Alane dissertou:

\begin{abstract}
Acredito que uma das maiores dificuldades a serem encontradas nessa fase será a de organização e análise dos dados para a escrita do trabalho individual, mas com a ajuda mútua dos demais integrantes da equipe essa dificuldade poderá ser superada. Conseguimos chegar ao resultado esperado com a proposta, e verifiquei de forma concreta que a calculadora pode contribuir com a aprendizagem dos alunos, junto com a argumentação (grifo nosso).
\end{abstract}

Foi muito proveitoso participar do projeto colaborativo OBEDUC, houve um crescimento tanto acadêmico como profissional e social. Conhecer pessoas novas, assim como seus objetivos de estudo é sempre bom. Aprendi que trabalhar de forma colaborativa não é uma tarefa fácil, mas que é possivel acontecer, desde que todos do grupo tenham um objetivo comum. Adquiri mais habilidade na escrita de trabalhos acadêmicos. Agradeço imensamente aos que me deram essa oportunidade, em especial à Dra. Abigail F. Lins (grifo nosso).

O professor de Matemática Genailson dissertou:

Apesar de ter melhorado, acredito que a escrita ainda será um desafio a ser vencido. Acredito que aprenderei como analisar e apresentar dados de uma pesquisa de forma relevante.

Para mim o maior ganho se deu no que diz respeito ao novo olhar para escola e seus agentes. As aprendizagens que obtive no projeto me proporcionaram um novo pensar e agir em práticas que adotava há anos (grifo nosso).

No relato de Genailson sobre descobertas e aprendizados para a Fase IV deixa cristalina a contribuição que foi a ele ter sido inserido no Projeto OBEDUC ao longo de três anos, em especial sua mudança de crenças e concepções durante seus longos anos de seu exercício na profissão (LÜDKE, 2006; IMBERNÓN, 2006; WAGNER, 2007). Além de Genailson ter evoluído em termos de leituras, debates e pesquisa, para ele o maior ganho em ter feito parte do Projeto OBEDUC foi o seu repensar, refletir e mudar sua própria prática. Ambos, Genailson e Alane, puderam verificar o quanto as propostas didáticas, frutos de suas pesquisas ao longo dos três anos do Projeto OBEDUC, foram frutíferas aos alunos, de como contribuíram para a compreensão e aprendizagem matemática dos alunos no entrelace da teoria e prática alcançadas por eles ao longo do Projeto OBEDUC (COCHRAN-SMITH e LYTLE, 1999). Tanto Alane quanto Genailson apontam a ainda incerteza e dificuldade em suas escritas acadêmicas, mas certificando que o trabalho colaborativo, o ambiente gerado entre eles com base na colaboração, estaria os auxiliando e superando suas ainda dificuldades (JAWORSKI, 2008; IBIAPINA; 2008). 


\section{COMENTÁRIOS FINAIS}

No presente artigo discutimos o processo ao longo dos três anos de execução de nosso Projeto OBEDUC em rede Núcleo UEPB de alguns de seus membros, professores em formação e em exercício, comprovando a vital importância de apoio governamental para recursos financeiros de atividades no desenvolvimento pré-profissional e profissional, assim como recursos financeiros de atividades na pesquisa. Foi de experiência única e enriquecedora aos dois graduandos, professores em formação, membros bolsistas do Projeto OBEDUC, terem tido a oportunidade de inserção ativa em um projeto envolvendo pesquisa na educação. Os relatos de Valbene e Helder representam e resultam suas participações no Projeto, confirmando o retorno benéfico do recurso financeiro proporcionado a eles a nível governamental.

Houve apoio irrestrito dos gestores das escolas envolvidas em nosso Projeto OBEDUC, assim como dos professores de Matemática das escolas, o que nos permite afirmar que as escolas públicas brasileiras estão permanentemente de portas abertas a projetos de pesquisa na educação, de apoio ao crescimento, qualificação e desenvolvimento de seus profissionais.

Os relatos de Valbene e Helder também nos permite afirmar que não estamos formando bem nossos professores, tão pouco nossos pesquisadores, em nossos cursos de graduação, as Licenciaturas. Necessitamos de urgentes mudanças em nossos cursos de formação de professores, assim como repensarmos nossas práticas enquanto formadores de professores e de pesquisadores.

Os relatos de Alane e Genailson, professores de Matemática em exercício, inseridos ativamente em nosso Projeto OBEDUC, mostraram que reuniões regulares e sistemáticas ao longo dos três anos do Projeto OBEDUC, e dos três Seminários Anuais que organizamos, foram fundamentais e centrais para seus crescimentos e desenvolvimentos profissionais, gerando um tempo precioso de interação e aprendizado entre os professores em formação e em exercício, além do repensar suas próprias práticas, crenças e concepções.

A oportunidade de se planejar um projeto de pesquisa entre dois a quatro anos, como é o caso do Programa OBEDUC, faz com que possamos gerar de fato interação longínqua e de qualidade entre professores e pesquisadores em formação e em exercício.

Com isso, podemos afirmar fortemente que a implantação do Programa OBEDUC na CAPES provoca e problematiza novos rumos nas políticas educacionais de formação de professores e pesquisadores de nosso país ao proporcionar interação e trabalho de forma conjunta, ao integrar alunos de graduação, de pós-graduação e professores em exercício em um mesmo projeto, em um mesmo processo, com um mesmo objetivo. Acreditamos que o Programa OBEDUC da CAPES se dá, e pode ser entendido, como uma área de estudo para políticas educacionais da educação superior no país, tanto a nível graduação como a nível pós-graduação, como para desenvolvimento profissional.

Além desses, o Programa OBEDUC da CAPES, em especial a modalidade em rede, proporciona interação entre pesquisadores profissionais, coordenadores dos projetos, sendo algo que sabemos não ocorrer de forma frequente. São muitos os pesquisadores profissionais que passam por toda sua vida acadêmica e de pesquisa de forma solo, jamais interagindo com outros colegas pesquisadores, a trocar ideias e experiências, a passar por um processo de pesquisa de forma conjunta, coletiva e colaborativa. Somos também solitários na maior parte de nossa vida acadêmica. É como se precisássemos de sorte para nos agrupar em uma equipe de pesquisadores profissionais e trabalharmos de forma conjunta. Apesar de não ser foco em 


\section{autêntica}

nosso artigo discutir o processo de pesquisadores profissionais, coordenadores ou colaboradores de Projetos OBEDUC, entende-se ser algo necessário a ser exposto, explorado, discutido e debatido. Certamente este é outro grande ganho do Programa OBEDUC da CAPES, o de proporcionar interação entre pesquisadores profissionais brasileiros, um processo que nos faz refletir sobre nossas próprias práticas como formadores de professores e de pesquisadores. Há muito a discutirmos, refletirmos e mudarmos nesta vertente. Por isso, lutemos para que o Programa OBEDUC da CAPES tenha continuidade. Que o Programa OBEDUC da CAPES, apesar da crise financeira e política brasileira em que passamos no momento, não seja de forma alguma descartado, pois a interação e aproximação que o Programa OBEDUC oferece entre professores em formação e em exercício, pesquisadores em formação e em exercício, é algo mais que necessário e vital aos crescimentos e desenvolvimentos profissionais, acadêmicos e científicos de nosso país.

\section{AGRADECIMENTOS}

Agradecemos a CAPES pelo financiamento pleno de nosso Projeto OBEDUC em rede UFMS/UEPB/UFAL Edital 2012, viabilizando bolsas de estudo aos 46 membros, divulgação científica de nosso Projeto em congressos nacionais, internacionais e publicações, assim como material permanente e de custeio. 


\section{autêntica}

\section{REFERÊNCIAS}

BACHELARD, G. A formação do espírito científico: contribuição para uma psicanálise do conhecimento. São Paulo: Contraponto Editora Ltda, 309f, 1996.

BIRD, T.; LITTLE, J. W. How schools organize the teaching occupation. The Elementary School Journal. V. 86, n. 4, pp. 493-512, 1986.

COCHRAN-SMITH, M.; LYTLE, S. Relationships of Knowledge and Practice: Teacher Learning in Communities. Review of Research in Education, Publicado por American Educational Research Association. V. 24, pp. 249-305, 1999.

FULLAN, Michael e HARGREAVES, Andy. A Escola como Organização Aprendente: buscando uma educação de qualidade. $2^{a}$ ed.. Porto Alegre: Artes Médicas, 2000.

IBIAPINA, Ivana. M. L. M. Pesquisa Colaborativa: Investigação, Formação e Produção de Conhecimentos. Brasília: Líber Livro Editora, 2008.

IMBERNÓN, Francisco. Formação docente e profissional: formar-se para a mudança e a incerteza. $6^{a}$ ed. São Paulo: Editora Cortez, 2006

JAWORSKI, Barbara. Building and sustaining inquiry communities in mathematics teaching development: teachers and didacticians in collaboration. In: KRAINER, K. and WOOD, T. (orgs.). The International Handbook of Mathematics Teacher Education volume 3: Participants in Mathematics Teacher Education: Individuals, Teams, Communities and Networks. Rotterdam: Sense Publishers, 2008.

LÉVY, P. Cibercultura. São Paulo: Editora 34 Ltda, 231f, 1999.

LINS, A. F., PEREIRA, P. S. e CARVALHO, M. Collaborative research work project with teachers who teach mathematics at basic level education in the north east and center east Brazilian state schools. Anais do ICME13 $13^{\circ}$ International Congress on Mathematics Education (in press). Alemanha: Hamburgo, 2016a.

Impacto primeiro dos professores em exercício membros do projeto de pesquisa colaborativo OBEDUC em rede. Anais do /I/ CONEDU III Congresso Nacional em Educação (em impressão). Rio Grande do Norte: Natal, 2016b.

LÜDKE, M. A complexa relação entre o professor e a pesquisa. In: ANDRÉ, M. (Org.). O papel da pesquisa na formação e na prática dos professores. $5^{a}$ ed. Campinas: Papirus, pp. 27-54, 2006.

PEIXOTO, J. e CARVALHO, R. M. A. Os desafios de um trabalho colaborativo. Revista Educativa, PUC/Goiânia. V. 10, n. 2, pp. 191-210, 2007.

WAGNER, J. The unavoidable intervention of educational research: A framework for reconsidering research-practitioner cooperation. Educational Researcher. V. 26, n. 7, pp. 13-22, 1997. 